International Research Journal of Diabetes and Metabolism (DOI:10.28933/IRJDM)

\title{
Health care education in people with arterial hypertension and
} diabetes mellitus

\author{
Xavier, H.S1; Silva, L.M.E2; Santos, N.R.N.T.V3 \\ 1,2Residente do Programa de Residência Multiprofissional Integrada em Saúde da Família -UPE; \\ 3Mestranda no Curso de Mestrado Profissional em Saúde Pública do Instituto de Pesquisa Aggeu \\ Magalhães - FIOCRUZ/PE. Preceptora da Residência Multiprofissional Integrada em Saúde da \\ Família.
}

\section{ABSTRACT}

Introduction: The Hypertension and Diabetes Program (HIPERDIA), established in 2001 by the Ministry of Health, organizes the assistance to people with Hypertension and Diabetes, chronic diseases in evidence in public health. Assistance begins in primary health care, the main gateway to the Unified Health System's attention network, which has a fundamental role in the prevention and control of diseases, as well as health promotion with multidisciplinary and interdisciplinary care, considering individuals in its completeness. Objectives: To report on the experience of residents of the Integrated Multiprofessional Residency Program in Family Health, in the inclusion of health promotion activities in the HIPERDIA group in a Family Health Unit in the city of Recife-PE. Methodology: This is an experience report, with data collected from the field diaries of activities in the HIPERDIA group, from August to October 2017. The group operates weekly, with 15 to 25 members. Initiated with health education activity, with professionals. The methods used were talk wheels and group dynamics with themes related to health promotion. Results and Discussion: Health education activities contribute through the exchange of experiences, to individuals' autonomy in the care of their own health, directed to the expanded concept of health, that goes beyond the control of the disease, expecting the improvement of the quality of life and well-being. Conclusion: The activities contributed to an improvement in the quality of life and prevention of the factors conditioning the complications of chronic diseases. Discussions and exchange of knowledge based on the promotion of oral health, mental health, healthy eating, the importance of self-care, among others, have been built that have contributed to increase the bond with other participants of the group and with professionals, building together a care that provides greater autonomy and well-being.

Keywords: Diabetes; Educação em saúde; Hipertensão; Qualidade de vida / Diabetes; Health education; Hypertension; Quality of life

*Correspondence to Author:

Xavier, H.S

Residente do Programa de Residência Multiprofissional Integrada em Saúde da Família -UPE

How to cite this article:

Xavier, H.S; Silva, L.M.E; Santos, N.R.N.T.V. Health care education in people with arterial hypertension and diabetes mellitus. International Research Journal of Diabetes and Metabolism, 2018, 1:3

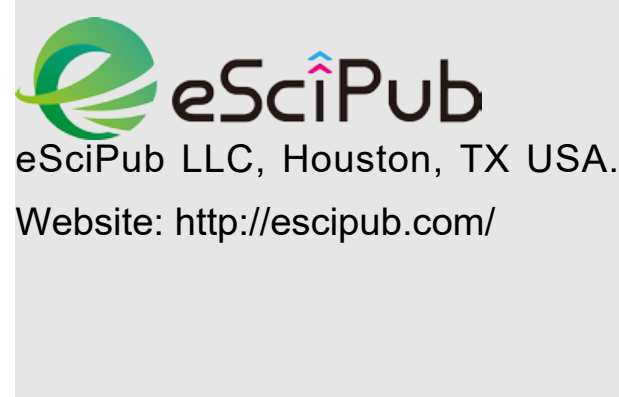

